\title{
İntestinal graft versus host hastalığının endoskopik bulgularının retrospektif değerlendirilmesi
}

\author{
Retrospective analysis of endoscopic findings in graft-versus-host disease of the gastrointestinal tract
}

Mustafa YAKUT ${ }^{1}$, Gülnihan KIRBAŞ², Arzu YUSIFOVA , Gülseren SEVEN ${ }^{1}$, Kubilay ÇINAR ${ }^{1}$, Ali ÖZDEN ${ }^{1}$

Ankara Üniversitesi Tıp Fakültesi Gastroenteroloji Bilim Dalı , Pediatrik Gastroenteroloji Bilim Dalı², Ankara

\begin{abstract}
Giriş ve Amaç: Akut graft-versus-host-hastalığı allojenik kemik iliği nakli sonrası aktive donör $T$ lenfositlerinin konakçı epitel hücrelerinin harabiyeti sonucunda meydana gelir. Allojenik kemik iliği nakli yapılan hastaların ortalama \%35-50'sinde akut graft-versus-host-hastalğı meydana gelir. Intestinal graft-versus-host-hastalğında endoskopik bulgular çeşitlilik gösterir. Hafif mukozal ödem, mukozal eritem, diffüz mukozal ödem, diffüz polipoid lezyonlar, multipl kanayan ülserler izlenebilir. Bu çalısmada graft-versus-hosthastalığı hastalarındaki endoskopik bulguları değerlendirdik. Gereç ve Yöntem: Hastanemizde endoskopik inceleme yapılan 18 allojenik kemik iliği nakli yapılmış intestinal graft-versus-host-hastalığında endoskopik bulgulan retrospektif olarak değerlendirildi. Bulgular: Bu çalışmada ortalama yaşı 33.9 ve \%62'sinin erkek olduğu allojenik kemik iliği nakli yapılan toplam 18 hasta değerlendirildi. Üst gastrointestinal sistem endoskopisi yapılan 6 hastada özofagus, mide ve duodenumda hafif mukozal eritem ve ödemden belirgin ülsere kadar çeșitli lezyonlar gözlendi. 12 hastaya kolonoskopi ve kolonoskopik mukozal biyopsi örneklemesi yapıldr. Kolonoskopik incelemede hafif mukozal ödemden kanayan ülsere kadar çeșitli lezyonlar izlendi. Sonuç: Intestinal graft-versus-host-hastalğı tanısında endoskopik görüntülemenin yeri önemlidir. Tanı için üst ve alt gastrointestinal sistemin mukozal biyopsi örneklemesi yapılmalıdır. Graft-versus-host-hastalı̆ının erken tanı ve tedavisinde endoskopik inceleme önemli rol oynar.
\end{abstract}

Anahtar kelimeler: Graft-versus-host hastalı̆̆ (GVHH), endoskopik bulgular

\section{GİRIŞ}

Graft-versus-host hastalığı (GVHH), donörden hastaya kök hücrelerle birlikte verilen sağlıklı T-lenfositlerinin neden olduğu şiddetli immünolojik reaksiyona bağlı organ fonksiyon bozukluğu ile giden siklıkla cilt, karaciğer ve gastrointestinal sistemi tutan bir hastalıktır (1). Transplantasyonu takip eden 2 yıl içinde kronik GVHH gelişme riski \%50-60 oranındadır (2). GVHH bağlı gastrointestinal tutulumun endoskopik görüntüleri çeşitlilik göstermektedir (3). Gastrointestinal GVHH tanısı endoskopik inceleme ve endoskopik mukozal biyopsi ile konmaktadır. GVHH hastalarının endoskopik değerlendirmesinde üst ve alt gastrointestinal sistemde (GIS) hafif mukozal eritem, ödem, belirgin ülserler, litik mukozal lezyonlar gibi çeşitli lezyonlar görülebilir (Resim 1). GVHH hastalarında gastrointestinal sistemin endoskopik incelemesinde lezyonların tutulumu fokal veya diffüz olabilir (4).
Background and Aims: Acute graft-versus-host disease occurs after allogeneic hematopoietic stem cell transplantation and is a reaction of donor immune cells against host tissues. Activated donor T cells damage host epithelial cells. About 35\%-50\% of hematopoietic stem cell transplant recipients will develop acute graft-versus-host disease. The endoscopic findings varied markedly and included mild mucosal edema with focal erythema, diffuse erythema, and diffuse polypoid indurations with multiple bleeding ulcerations. We investigated endoscopic findings in a graft-versus-host disease patient population. Materials and Methods: A retrospective review of endoscopic data was performed in 18 adult allogeneic bone marrow transplant recipients at our institution. Results: In this study, 18 allogeneic bone marrow transplant patients (mean age 33.9 years; $62 \%$ male) were evaluated. In 6 graftversus-host disease patients, the endoscopic appearances of the esophagus, stomach and duodenum varied from subtle mucosal erythema and edema to frank ulceration. Colonoscopy was performed with biopsies in 12 graft-versus-host disease patients. The colonoscopic findings varied markedly and ranged from mild mucosal edema with focal erythema to multiple bleeding ulcerations. Conclusions: The diagnostic accuracy of endoscopy was high in gastrointestinal graft-versus-host disease. Accurate diagnosis of gastrointestinal graft-versus-host disease might be obtained with mucosal biopsies from either the upper or lower gastrointestinal tract. Endoscopy may play a significant role in establishing early diagnosis and treatment for gastrointestinal graft-versus-host disease patients.

Key words: Graft-versus-host disease (GVHD), endoscopic findings

\section{GEREÇ VE YÖNTEM}

Eylül 2004 ile Mart 2009 tarihleri arasında Ankara Üniversitesi Tıp Fakültesi Gastroenteroloji Bilim Dalı Endoskopi Ünitesinde kemik iliği nakli sonrası GVHH değerlendirmesi için endoskopi ve endoskopik mukozal biyopsi yapılan 18 GVHH hastasının başvuru semptomları, endoskopik bulguları ve işlem komplikasyonları tıbbi kayıtlardan retrospektif olarak değerlendirildi. Hastalarımız standart videoendoskopi cihazı ile değerlendirildi.

\section{BULGULAR}

Hematolojik hastalıklar (KML, ALL, AML, myelodisplastik sendrom, aplastik anemi) nedeni ile kemik iliği nakli yapılan ve kemik iliği nakli sonrası karın ağrısı, bulantı, kusma, dışkılama değişikliği, rektal kanama gibi üst ve alt gastrointestinal sistem semptomları ile başvuran hastalarımızdan 6'sına gastroduodenoskopi ve 12'sine kolonoskopi işlemi yapıldı 


\begin{tabular}{|c|c|c|c|c|}
\hline Hasta no & Yaş & Cinsiyet & Rektosigmoidoskopi bulgusu & İşlem komplikasyonu \\
\hline 1 & 35 & K & $\begin{array}{l}\text { Inen, sigmoid kolon ve rektum proksimali ödemli, hiperemik, granüler } \\
\text { ve vasküler yapılar silinmiş }\end{array}$ & Yok \\
\hline 2 & 28 & $\mathrm{E}$ & Rektosigmoid kolon mukozası normal & Yok \\
\hline 3 & 22 & E & 40 cm'e kadar mukoza ödemli, hiperemik, yer yer erozyonlar & Yok \\
\hline 4 & 38 & E & Rektum mukozası ödemli & Yok \\
\hline 5 & 19 & E & Rektum ve sigmoid kolonda 3-4 mm'lik erozyonlar & Yok \\
\hline 6 & 37 & E & Rektum hafif ödemli, yer yer hiperemik alanlar & Yok \\
\hline 7 & 31 & $\mathrm{~K}$ & Rektum mukozası hafif ödemli & Yok \\
\hline 8 & 40 & K & 30 cm'ye kadar mukoza ödemli ve yer yer hemorajik alanlar, proksimal kolon normal & Yok \\
\hline 9 & 29 & E & Rektosigmoid bölgede hemorajik yüzeyel ülserler & Yok \\
\hline 10 & 37 & $\mathrm{~K}$ & Mukoza ödemli, hiperemik ve mukozal peteşiler & Yok \\
\hline 11 & 38 & E & Sigmoid kolonda ülserler & Yok \\
\hline 12 & 54 & E & Rektosigmoid mukoza ödemli, hiperemik & Yok \\
\hline
\end{tabular}

(Tablo 1). Hastalarımızın ortalama yaşı 33.9 idi. Hastalarımızdan 7'si kadın 1l'i erkekti. Gastroduodenoskopi işleminde özofagus, korpus, antrum ve duodenum biyopsileri alındi. Kolonoskopi işlemi sırasında tüm hastalarda splenik fleksuraya kadar ilerlendi ve rektosigmoid bölge mukoza biyopsileri alındı. Endoskopik biyopsi işlemi sırasında trombositopeni nedeni ile hastalar kanama yönünden dikkatle izlendi ancak hiçbir hastada komplikasyon görülmedi. Hastalarımızın endoskopik bulguları çeşitlilik gösteriyordu. Normal mukozadan, ağır mukozal hasara kadar çeşitli lezyonlar izlendi. Üst gastrointestinal inceleme yaplan tüm hastalarda midede mukozal hiperemi ve erozyonlar mevcuttu. Ayrica gastroduodenoskopi yapılan 6 hastadan 3'ünde özofagus ve 2 hastada da duodenum lezyonları mevcuttu (Tablo 2).

\section{TARTIŞMA}

GVHH, donörden hastaya kök hücrelerle birlikte verilen sağlıklı T-lenfositlerin neden olduğu şiddetli immünolojik reaksiyona bağlı organ fonksiyon bozukluğu ile giden bir klinik sendrom olup allojenik kök hücre naklinden sonra başlıca mortalite ve morbidite sebebidir. Kronik GVHH ortalama 3 aydan sonra ortaya çıkar ve kemik iliği naklinin uzun dönem sonuçlarını ve yaşam kalitesini belirler (5). Transplantasyonu takip eden 2 yll içinde kronik GVHH gelişme riski \%50-60 olup en büyük risk faktörü hikayede daha önce akut GVHH'nin olmasıdır (2).

GVHH patogenezinde alıcı cilt, mukozalar, karaciğer ve barsak hücrelerindeki allojenik MHC Class II moleküllerine karşı donör CD4+T hücre aktivasyonu ve sonrasında IL-2, IL-4 ve IL-10 salınımı başlıca rol oynar. Akut GVHH patogenezinde donör CD8+T hücreleri, kronik GVHH patogenezinde donör CD4+T hücreleri rol oynar (6).

Kronik GVHH tanısı, klinik ve laboratuvar parametrelere göre konur. Kronik GVHH tanısı ortalama 100. günden sonra konur (7). GVHH slklıkla cilt, karaciğer ve gastrointestinal trakt tutulumu ile seyreder (1). Kronik GVHH'de genellikle başlangıçta cilt lezyonları görülür.

GVHH'nin alt gastrointestinal sistem tutulumuna bağlı sekretuvar diyare, abdominal ağrı ve rektal hemoraji görülebilir. GVHH'nin üst gastrointestinal tutulumuna bağlı anoreksi, dispepsi, yiyecek intoleransı, bulantı ve kusma görülebilir.

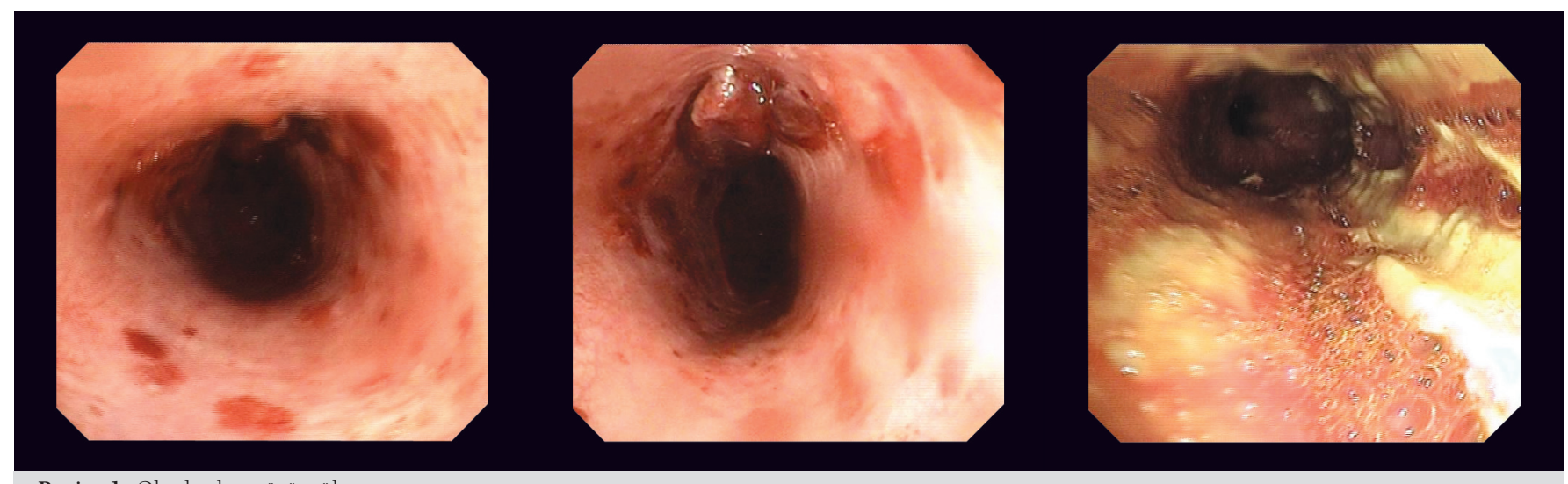

Resim 1. Olgulardan görüntüler. 


$\begin{array}{ccclc}\text { Tablo 2. Ust gastrointestinal inceleme yapilan GVHH hastalarının endoskopik bulguları } & \text { Işlem komplikasyonu } \\ \text { Hasta no } & \text { Yaş } & \text { Cinsiyet } & \text { Gastroduodenoskopi bulgusu } & \text { Yok } \\ 1 & 30 & \text { E } & \text { Özofagusta lineer erozyonlar ve ülserler, mide ödemli hiperemik } & \text { Yok } \\ 2 & 37 & \text { K } & \text { Antrumda üzeri ülsere lineer erozyonlar, duodenum ödemli lineer erozyonlar } & \text { Yok } \\ 3 & 40 & \text { K } & \text { Tüm mide mukozası ödemli, hiperemik, prepilorik bölgede milimetrik boyutta ülserler } & \text { Yok } \\ 4 & 46 & \text { K } & \text { Tüm mide mukozası eritemli } & \text { Yok } \\ 5 & 29 & \text { E } & \text { Özofagusta 5-6 mm'lik ülserler, duodenumda erozyonlar } & \text { Yok } \\ 6 & 22 & \text { E } & \text { Özofagusta lizis görünümü ve yüzeyel ülserler, tüm mide mukozası hiperemik ve ödemli } & \end{array}$

GVHH hastalarının gastrointestinal semptomları tedaviye oldukça duyarlıdır (8). GVHH hastalığına bağlı gastrointestinal tutulumun endoskopik görüntüleri çeşitlilik göstermektedir (3). Endoskopik değerlendirmede hafif mukozal eritem, ödem, belirgin ülserler, litik mukozal lezyonlar gibi değişik lezyonlar görülebilir (Resim 2). GVHH hastalarında gastrointestinal sistemin endoskopik incelemesinde lezyonların tutulumu fokal veya diffuz olabilir (4). GVHH'nin gastrointestinal tutulumunda tipik endoskopik bulgu olmamakla birlikte gastrointestinal mukozal düzensizlik ve kanama yaygın bulgular arasındadır (2). Bir çalışmada GVHH'nin endoskopik değerlendirmesinde hastaların tümünde mukozal düzensizlik ve mukozal eritem, \%85'inde mukozal erozyonlar, hastaların, \%71'inde mukozada kolay kanama ve hastalarm \%71'inde duodenal tutulum olduğu gösterilmiştir (9). Başka bir çalışmada endoskopik incelemede hafif mukozal ödem, fokal eritem, diffüz eritem, diffuz polipoid görünüm ve multipl kanayan ülserler şeklinde lezyonlar olabileceği tanımlanmıştır (10).

GVHH hastalarinda özofagus tutulumunda deskuomatif lezyonlar, ülserler ve vezikülobüllöz lezyonlar görülebilir (11). Kronik dönemde GVHH'ye bağlı özofagus tutulumunda veb ve halka şeklinde veya gittikçe daralan şekilde özofagus daralması görülebilir (12).

Üst gastrointestinal sistem endoskopisi yaptığımız 6 hastanın tümünde mukozal hiperemi ve midede erozyonlar mevcuttu. Üç hastamızda özofagusta ülserler mevcuttu. Bir hastada özofagusta yaygin mukozal litik lezyonlar mevcuttu. İki hasta- mizda da duodenum tutulumu vardı.

GVHH masif hemoraji ile birlikte ince barsak ve kolonda yaygın ülserler ile seyredebilir (13). Endoskopik inelemede jejunum, terminal ileum ve kolonda hemorajik ülserler görülebilir (13). Bazı çalışmalarda intestinal GVHH'nin sıklıkla ince barsak tutulumuna neden olduğu bildirilmiştir (14). GVHH tanısı endoskopik biyopsi ile konulur. Bir çalışmada endoskopik tanının duyarlılığını değerlendirmek için 112 hastada mide, duodenum ve sigmoid kolondan alınan biyopsi örnekleri değerlendirilmiş ve retosigmoid bölge biyopsi örneklemesinin daha sensitif olduğu bulunmuş. Bu çalışma sonucunda rektosigmoid bölgeden tek biyopsi örneğinin tanı için yeterli olduğu bildirilmiş (15). Kolonoskopi incelemesi yaptığımız 12 hastamızda da sadece splenik fleksuraya kadar değerlendirme yapıldı. 18 hastamızdan 12'sine rektosigmoid inceleme ile sigmoid kolon mukozasından biyopsi örneklemesi yapıldı. Bir hastada rektosigmoid mukoza normal görünümdeydi. Üç hastada rektosigmoid mukozada ülserler, dört hastada da rektosigmoid mukozada hiperemi ve dört hastada rektosigmoid mukozada erozyonlar vardi. Trombositopeni nedeni ile GVHH hastalarında endoskopik mukozal biyopsiye bağlı gastrointestinal sistem kanaması görülebileceği bildirilmiştir (1). Endoskopik biyopsi yaptığımız hiçbir hastada gastrointestinal kanama komplikasyonu izlenmedi.

GVHH hastalığının intestinal tutlumunda endoskopik görünüm histolojik özellikler ile koreledir. Bir çalışmada; kemik iliği nakli yapılan 44 hastaya 96 endoskopik inceleme ve 162

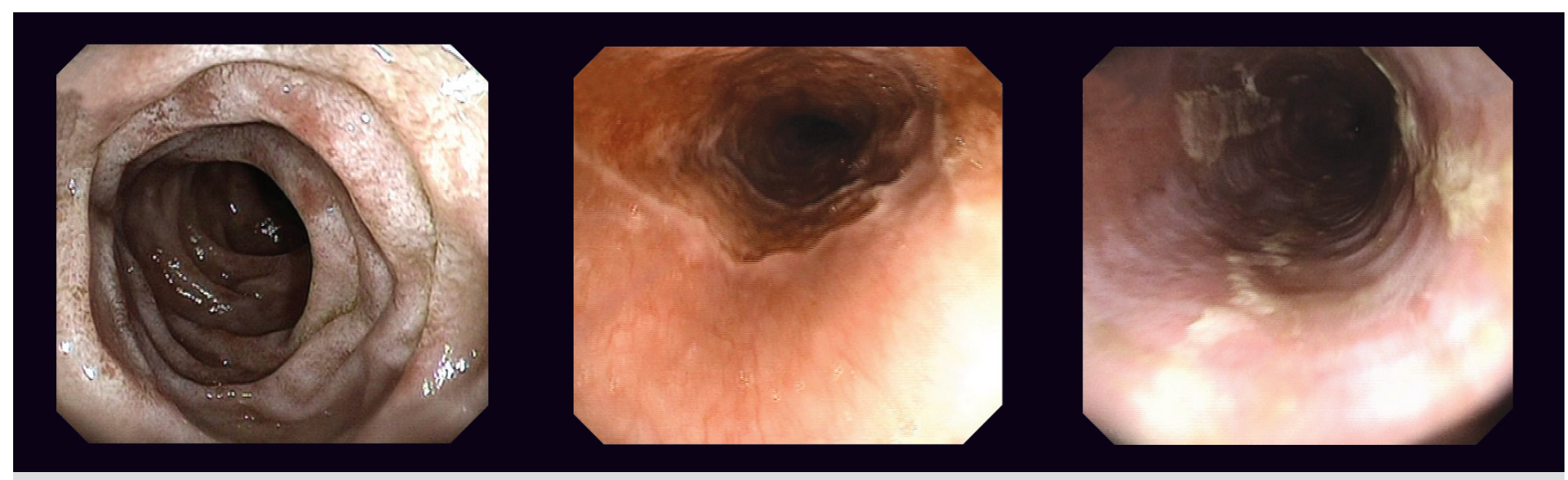

Resim 2. Olgulardan görüntüler 
endoskopik biyopsi yapılmış ve bu çalışmada endoskopik görünüm ile mikroskopik özelliklerin uyumlu olduğu gösterilmiştir (16). 101 kemik iliği nakli hastasının incelendiği başka bir çalışmada; GVHH hastalarında endoskopik bulguların histolojik bulgularla yüksek derecede korele olduğu bulunmuştur (17). GVHH tanısı için en iyi endoskopik işlemin hangisi olduğu tartışmalıdır. 24 GVHH hastasında mide, duodenum, ileum, sağ kolon ve rektosigmoid kolon biyopsileri alınmış. Bazı çalışmalarda üst ve alt gastrointestinal sistemden alınan biyopsi örneklerinin GVHH tanısı açısından eşit sensitiviteye sahip olduğu bildirilmiştir. Diyare şikayeti olan hastalardalar rektosigmoid böldgeden alınan biyopsilerin nisbeten daha sensitif olduğu bildirilmiş̦tir (18).

GVHH hastalarında histopatolojik değişiklikler posttransplant ilk 100 gün içinde oluşur. Gastrointestinal mukoza hücrelerinde nekroz ve rejenerasyon görülür. Ileri dönemde kript torsiyonu ve mukozanin ciddi harabiyeti olur. Kronik dönemde mukoza ve submukoza fibrozisi görülür (19). Endoskopik biyopside apoptozisin gösterilmesi tanıyı oldukça destekleyicidir (1). Kronik dönemde ileri evrede görülen subserozal fibrozise bağlı mukozal biyopsiler tanı koydurucu olmayabilir (20).

GVHH'de GIS tutulumu ciddi ve hastaya rahatsizlık veren bir komplikasyondur. Donör T hücrelerinin azalması GVHH ris- kini azaltır ancak primer hasatalığın nüks riski artar. GVHH'ye bağlı gastrointestinal tutulumda endotoksinlerin barsaktan translokasyonu olur, bu da enfeksiyonlara neden olur. Lipopolisakkarid endotoksinlerin translokasyonunu önlemek için sistemik antibakteriyel proflaksi uygulanmalıdır (21). GVHH hastalığı için risk altında bulunan hastaların da CMV enfeksiyonu yönünden yakından izlenmesi gerekir. Kolestazı olan sarılıklı hastalarda ursodeoksikolik asit \%30 oranında iyileşme sağlamaktadır. Yeterli kalori alamayan hastalar damardan total beslenme ya da enteral beslenme tüpleriyle beslenme ihtiyacı duyabilirler. Uzun süre steroid alan hastalarda osteopeni riski nedeni ile kalsiyum desteği düşünülmelidir (22). GVHH'e bağlı üst gastrointestinal sistem şikayetleri tedaviye oldukça duyarlıdırlar (23). GVHH tedavisinde kortikosteoid tedavisi faydalıdır. GVHH tedavisinde 2 $\mathrm{mg} / \mathrm{kg} /$ gün kortikosteroid tedavisi ile $\% 70$ oranında remisyon, \%62 oranında da 3 yıllık remisyon sağlandığı bildirilmiștir. Günümüzde GVHH'nin tedavisinde siklosporin ve klsa dönem metotreksat sık kullanılır (2). Takrolimusun siklosporine ilave faydası gösterilememiştir. Steroid refrakter olgularda budesonid veya infliksimab tedavisi faydalı olabilir (1). Intestinal GVHH hastalı̆ı̆ını patogenezinin ülseratif kolitle benzerliği nedeni ile sulfasalazin, betametazon enema ve eicosapentaenoic acid (EPA) kullanımı faydalıdır (21).

\section{KAYNAKLAR}

1. Ross WA, Couriel D. Colonic graft-versus-host disease. Curr Opin Gastroenterol 2005;21:64-9.

2. Jacobsohn DA, Vogelsang GB. Acute graft versus host disease. Orphanet J Rare Dis 2007;2:35

3. Iqbal N, Salzman D, Lazenby AJ, Wilcox CM. Diagnosis of gastrointestinal graft-versus-host disease. Am J Gastroenterol 2000;95:3034-8.

4. Ponec RJ, Hackman RC, McDonald GB. Endoscopic and histologic diagnosis of intestinal graft-versus-host disease after marrow transplantation. Gastrointest Endosc 1999;49:612-21.

5. Williams M. Gastrointestinal manifestations of graft-versus-host disease: diagnosis and management. AACN Clin Issues 1999;10:500-6.

6. Doutrelepont JM, Moser M, Leo O, et al. Hyper IgE in stimulatory graftversus-host disease: role of interleukin-4. Clin Exp Immunol 1991;83: 133-6.

7. Lee SJ, Klein JP, Barrett AJ, et al. Severity of chronic graft-versus-host disease: association with treatment related mortality and relapse. Blood 2002; 100:406-14.

8. Weisdorf DJ, Snover DC, Haake R, et al. Acute upper gastrointestinal graft-versus-host disease: clinical significance and response to immunosuppressive therapy. Blood 1990;76:624-9.

9. Funakoshi K, Kato T, Ohta T. GVHD gastro-duodenitis. Nippon Rinsho 2004;62:541-5.

10. Yeh SP, Liao YM, Hsu CH, et al. Gastric bleeding due to graft-vs-host disease: discrepancy between endoscopic and histologic assessment. Am J Clin Pathol 2004;122:919-25.

11. Nakshabendi IM, Maldonado ME, Coppola D, Mamel JJ. Esophageal cast: a manifestation of graft-versus-host disease. Dig Dis 2000;18:103-5.

12. McDonald GB, Sullivan KM, Plumley TF. Radiographic features of esophageal involvement in chronic graft-vs.-host disease. AJR Am J Roentgenol 1984;142:501-6.

13. Saito H, Oshimi K, Nagasako K, et al. Endoscopic appearance of the colon and small intestine of a patient with hemorrhagic enteric graft-vs.host disease. Dis Colon Rectum 1990;33:695-7.

14. Neumann S, Schoppmeyer K, Lange T, et al. Wireless capsule endoscopy for diagnosis of acute intestinal graft-versus-host disease. Gastrointest Endosc 2007;65:403-9.

15. Ross WA, Ghosh S, Dekovich AA, et al. Endoscopic biopsy diagnosis of acute gastrointestinal graft-versus-host disease: rectosigmoid biopsies are more sensitive than upper gastrointestinal biopsies. Am J Gastroenterol 2008;103:982-9. Epub 2007 Nov 19.

16. Cruz-Correa M, Poonawala A, Abraham SC, et al. Endoscopic findings predict the histologic diagnosis in gastrointestinal graft-versus-host disease. Endoscopy 2002;34:808-13.

17. Cheung DY, Kim JI, Kim SS, et al. Endoscopic evaluation in gastrointestinal graft-versus-host disease: comparisons with histological findings. Dig Dis Sci 2008;53:2947-54. Epub 2008 Apr 10.

18. Thompson B, Salzman D, Steinhauer J, et al. Prospective endoscopic evaluation for gastrointestinal graft-versus-host disease: determination of the best diagnostic approach. Bone Marrow Transplant 2006;38:371-6.

19. Akpek G, Chinratanalab W, Lee LA, et al. Gastrointestinal involvement in chronic graft-versus-host disease: a clinicopathologic study. Biol Blood Marrow Transplant 2003;9:46-51.

20. Snover DC. Graft-versus-host disease of the gastrointestinal tract. Am J Surg Pathol 1990;14(Suppl 1): 101-8.

21. Takatsuka H, Iwasaki T, Okamoto T, Kakishita E. Intestinal graft-versushost disease: mechanisms and management. Drugs 2003;63:1-15.

22. Vogelsang GB. How I treat chronic graft-versus-host disease. Blood 2001;97:1196-201.

23. Wakui M, Okamoto S, Ishida A, et al. Prospective evaluation for upper gastrointestinal tract acute graft-versus-host disease after hematopoietic stem cell transplantation. Bone Marrow Transplant 1999;23:573-8. 